\title{
Is Adipocyte Differentiation the Default Lineage for Mesenchymal Stem/Progenitor Cells after Loss of Mechanical Loading? A Perspective from Space Flight and Model Systems
}

\author{
David A. Hart ${ }^{1,2}$ \\ ${ }^{1}$ McCaig Institute for Bone \& Joint Health University of Calgary, Calgary, Canada \\ ${ }^{2}$ The Centre for Hip Health \& Mobility, Department of Family Practice, University of British Columbia, \\ Vancouver, Canada \\ Email: hartd@ucalgary.ca
}

Received 30 May 2014; revised 17 July 2014; accepted 31 July 2014

Copyright (C) 2014 by author and Scientific Research Publishing Inc. This work is licensed under the Creative Commons Attribution International License (CC BY). http://creativecommons.org/licenses/by/4.0/

(c) (i) Open Access

\begin{abstract}
Mesenchymal stem/progenitor cells (MSC/MPC) are found in many tissues and fluids including bone marrow, adipose tissues, muscle, synovial membranes, synovial fluid, and blood. Such cells from different sources can proliferate and differentiate into different lineages (e.g. osteogenic, chondrogenic and adipogenic) after suitable stimulation. However, details regarding the regulation of MSC/MPC proliferation and differentiation status are still unclear and it is likely that regulation involves both biological and mechanical influences in the different environments. It has been noted that in humans and preclinical animal models that exposure to microgravity/space flight or prolonged bed rest (a surrogate for microgravity) can lead to infiltration of skeletal muscle and bone marrow with fat. Similarly, in preclinical models treated with multiple intramuscular injections of Botulinum Toxin $A$ to induce muscle weakness and atrophy, there is also an infiltration of the muscle with fat. The origins and basis for these fat deposits are largely unknown, but there is a possibility that the altered mechanical and biological environments lead to dysregulation of MSC/MPC and progression to preferential differentiation towards the adipocyte lineage. Furthermore, loss of MSC regulatory control by either mechanical and/or biological factors may also contribute to their involvement in obesity development and progression. Thus, the utility of using MSC/MPC from some sources for tissue engineering purposes may be compromised and further research regarding optimal loading for tissue engineering purposes is likely warranted.
\end{abstract}


Keywords

Mesenchymal Stem Cells, Adipose-Lineage, Microgravity, Bed Rest, Muscle Weakness, MSC
Regulation, Adipose Tissue

\section{Introduction}

\subsection{Mesenchymal Stem/Progenitor Cells}

Mesenchymal stem/progenitor cells (MSC/MPC) are found in a number of tissues and compartments including blood, placenta, bone marrow, synovial membrane, synovial fluid, fat (infrapatellar fat pad of the knee, subcutaneous fat, abdominal fat) (reviewed in [1] [2]). Such cell populations are heterogeneous [1] [2] with respect to proliferation and differentiation [3], and MSC/MPC from different compartments (e.g. bone marrow and other compartments) exhibit different epigenetic signatures, indicating that the local environment influences the MSC/MPC populations (discussed in [1] [2]). MSC/MPC populations in different compartments appear to be able to migrate to other sites via the cardiovascular system (reviewed in [4]-[6]; and others), but the stimuli for such migratory patterns is not well defined as yet.

The MSC/MPC from different tissues and compartments appear to differ with respect to their predilection to differentiate towards different lineages (e.g. bone, cartilage, adipose/fat cells) ([3]; and others). Thus, those in the bone marrow appear to prefer to differentiate towards bone cell phenotypes, while those in the synovial membranes or synovial fluid of the knee prefer chondrogenesis ([3] [7]; and others). With MSC from sources such as fat and fat pads, the phenotype of the cells appears to be more anti-inflammatory than those from other sources, and they are being widely investigated for applications such as osteoarthritis, rheumatoid arthritis, and others (reviewed in [8]).

\subsection{Control of MSC Numbers, Distribution, and Activity}

Levels of MSC in blood are reported to decline with age (discussed in [9] [10]; and others). In addition, numbers of MSC in skeletal muscle are reported to be influenced by the sex of animal, with females having more MSC than males [11]. Gender dimorphisms in progenitor and stem cell functions have also been noted [12]. In rats, it has been reported that MSC can be induced to emigrate from the bone marrow into the blood stream, and then home towards sites of need via specific mediators (e.g. the neuropeptide Substance P) from such injury sites [13]. Interestingly, injection of large numbers of MSC into the blood stream (discussed in [5]) or into the injured knee joint [14] or other tissues [15] leads to very small numbers of the injected cells actually residing at the sites for an extended period of time. Thus, such populations are likely very heterogeneous with regard to homing, localization and fate, for reasons which are still mostly unclear (discussed in [1] [2]).

Some of the response patterns noted may be the result of specific features of the different environments both biologically and mechanically. For instance, one might expect that MSC would be able to initiate repair following an injury to a connective tissue. However, it was found that an inflammatory environment resulting from an injury leads to impaired function of MSC within a knee joint [7] [16]. Furthermore, while it might be expected that all environments exert some biomechanical influences on MSC (pulsatile loading in blood, intermittent compression in synovial fluid, aspects of shear in bone marrow due to loading of the bone), the mechanical environment of cells in synovial fluid or the infrapatellar fat pad would likely be quite different from that in subcutaneous fat. Thus, MSC are able to exist and function in quite diverse biological and mechanical environments.

That the biological environment can impact MSC regulation can be drawn from the literature. For instance, normal MSC from synovial fluid are able to differentiate along different lineages in vitro in response to specific stimuli [3], and in fact are capable of aggregating as they differentiate towards the chondrogenic lineage [16] [17]. However, MSC/MPC isolated from individuals with early osteoarthritis or following an injury leading to an inflammatory state are reported to have lost this attribute [17]. Similarly, MSC isolated from ovine knee synovial fluid are compromised if the knee has been subjected to an injury [3].

An additional biological contributor to MSC regulation in different environments that has not received much 
attention is the nerve supply and mediators contained in such elements. Nearly all tissues are innervated (with articular cartilage a notable exception), including fat pads, bone, bone marrow, synovial membranes and joint capsules to name a few. Obviously, fluid components such as blood or synovial fluid are not innervated, but synovial fluid can be exposed indirectly to nerves via released mediators and neural influences on cells of the microcirculation are well known. However, while the nerve supply in many tissues is modest at best, it is clear that cells such as mast cells often co-localize with nerves and are capable of amplifying neural signals (reviewed in [18]-[21]). Thus, the impact of a few nerves on other resident cells may be a direct influence (e.g. nerve elements on MSC directly), or indirectly via amplification through other cells (e.g. nerve-mast cell-MSC). Some of this discussion is speculative at the present time, as nerve-MSC interactions and regulatory considerations have not been explored in any detail.

On the larger scale, the relative interplay between biological and mechanical variables in maintaining MSC in a "meta-stable" state in various tissues and fluids, is not well characterized (discussed in [22]). Thus, the question of how MSC numbers are stabilized in various tissues, and how the cells are kept in the MSC/MPC state in the face of a large number of potential activators and inhibitors, has not been addressed well in the literature, in fact such questions have not been addressed in the available literature based on this author's search of databases. This situation leads to several questions including the following: 1) what are the cellular mechanisms that maintain a balance between the MSC "state"?; 2) how is the need to replenish MSC when they are used for tissue repair or response to injury regulated?; and 3) if such regulatory systems become compromised (e.g. via aging, abnormal environments, or chronic diseases), what are the consequences with regard to MSC integrity? What follows is a discussion regarding potential answers to such questions, and possible research directions to address current gaps in our understanding.

\section{Skeletal Muscle Responses to Botulinum Toxin A (BoToxA) in Preclinical Models}

As noted through studies of animal models, MSC are present in the perivascular compartment of many skeletal muscles [23]-[25], with some sex differences in numbers and activity also noted (discussed in [23]-[25]). These MSC can be differentiated into the usual three lineages (osteogenic, chondrogenic, adipogenic) after isolation, as well as possibly others (e.g. myogenic, neural).

Injection of skeletal muscles of the rabbit hind leg with repeated doses of BoToxA leads to the rapid atrophy of the muscles with loss of function [26] [27]. Subsequent to the atrophy, there is a "fatty infiltration" of the muscles which persists for some time (discussed in [28]). The source or origins of the fatty infiltrate has not been characterized, and the findings are more descriptive than mechanistic thus far. Therefore, based on the temporal relationships, following BoToxA injection the overt atrophy occurs rapidly, and then in response to prolonged loss of mechanical integrity of the muscle, a fatty infiltrate occurs somewhat later, but which can be protracted. The fate of the muscle-associated MSC has not been addressed in this situation based on a search of the literature. In addition, the fate of MSC within existing fat pads of the knee, such as Hoffa's fat pad, during such BoToxA-induced atrophy has not been described, but these issues are currently under investigation (unpublished).

\section{3. "Fatty Infiltrate" Responses to Micro-Gravity or Prolonged Bed Rest}

Rapid atrophy of muscle and bone upon exposure to micro-gravity through space flight has long been known (reviewed in [29]-[31]; and others). Such loss occurs throughout the body, but appears to be focused on a subset of muscles of the lower extremities which are apparently the most influenced by the 1G-mediated ground reaction forces on earth. While the muscle loss can be at least partially prevented by counter measures, bone loss is less influenced by existing modalities (reviewed in [32]). Interestingly, the extent of bone and muscle loss by those experiencing micro-gravity in space flight is quite individualized, with some people losing tissue mass at rates several times faster than others (e.g. $2 \% /$ month vs $0.2 \% /$ month) (discussed in [33]). Thus, there appears to be a genetic component to the rate of loss that is not overtly expressed when in the $1 \mathrm{G}$ environment (possibly silent mutations that are masked by the $1 \mathrm{G}$ environment). Some authors have suggested that the responses to microgravity and space flight are actually an accelerated aging scenario [34]-[36]. If the analogy is correct, then finding solutions to responses to microgravity may have application for aging earth-bound populations as well.

Interestingly, with prolonged exposure to micro-gravity, there is a reported "fatty or lipid infiltration" of the muscle (reviewed in [37]). Where such fatty infiltrates come from, or why they appear has not been addressed, 
the phenomenon merely described. The recovery from such fatty infiltrates after a return to a $1 \mathrm{G}$ environment is apparently slow, but has not been described well in the literature (but likely could using improved ultrasound methodology or others). With six team members on the International Space Station presently for $\sim 6$ month stays, the number of individuals who could be monitored for onset and recovery is quite large by space-study standards. Similarly, one could perform a limited number of muscle biopsies to evaluate fat-associated MSC in such astronauts.

A surrogate for exposure to micro-gravity is "head down-tilt bed rest" (reviewed in [38] [39]; and many others). Individuals subjected to this type of bed rest develop rapid bone loss indicators [40], and subsequently muscle atrophy, overt bone loss, and other characteristics of space flight (reviewed in [31] [38] [39]; and many others). Over time, individuals exposed to this environment also develop “fatty infiltrates” in their skeletal muscle and other tissues. And again, the condition has been described, but the source and causes have not been addressed. While this surrogate has been studied in relation to micro-gravity aspects, it is also clear that with the aging population, many of whom are confined to prolonged bed rest conditions, there is also risk for atrophy and other complications, including "fatty infiltration" of their skeletal muscles and other tissues [41], and some counter measures prevent such accumulation [42].

Therefore, in the Botulinum toxin studies, the space flight/microgravity studies, and the bed rest studies, as well as other animal studies of weightlessness (e.g. hind limb elevation to mimic loss of ground reaction forces) (reviewed in [37] [43]), an accumulation of fat/lipid infiltrates occurs during prolonged exposure to the altered environment. It is clear that it happens, but the why and how it happens still remains to be determined. One possibility that could explain at least some of this response to weightlessness or loss of mechanical integrity is that mesenchymal stem cells in muscle and bone marrow are maintained in a meta-stable state by mechanical loading of the tissues, directly (via the MSC themselves) or indirectly via loading effects on the neuronal state of the tissues which when compromised, leads to a loss of the maintenance of the MSC in such a meta-stable state. Thus, alterations in these influences on MSC regulation may lead to the preferential differentiation of the MSC towards the adipose lineage (the default response). This may be due to an enhanced responsiveness to lineage-specific signals in the environment, or to an intrinsic loss of stability in the MSC.

While there is not much in the literature regarding this possibility, certainly the report of Meyers et al. [44] indicates that in a model of microgravity, there is enhanced adipogenesis and reduced osteoblastogenesis by human MSC. Interestingly, recent studies from the author's laboratory have indicated that a subset of cloned MSC/MPC from porcine synovial fluid are restricted to differentiating towards either the osteogenic or adipogenic lineages ([3]; JJ Kutcher, MSc Thesis, University of Calgary, 2012; Kutcher et al., in preparation). While not the dominant phenotype of MSC from porcine synovial fluid, the prevalence of this unique subset of MSC in other compartments such as muscle, bone marrow, and adipose tissue (e.g. abdominal fat, subcutaneous fat, Hoffa's fat pad of the knee, brown fat) is unknown. Relevant to this point is also the fact that the studies by Meyers et al. [44] used mixed populations of human MSC, so it was not possible to make conclusions regarding whether only a subpopulation of MSC were affected by the microgravity conditions employed. Thus, it would be relevant to repeat those studies with well characterized cloned cells to allow stronger conclusions to be made. Such studies are currently underway (unpublished).

While the above question has not been answered directly, there are reports that mechanical loading can influence MSC lineage specificity even when the subjects are in the $1 G$ environment of earth [45] [46]. Thus, low magnitude mechanical stimulation of C57BL/6 male mice promoted bone formation and depressed/inhibited diet-induced obesity. There were also increases in bone marrow MSC numbers following such stimulation. A pilot study with 48 young females also indicated that this low magnitude mechanical stimulation enhanced bone formation and kept visceral fat at baseline levels. Thus, unique mechanical loading regimens in a $1 \mathrm{G}$ environment may also be a methodological approach to interfere with obesity development [45] [46]. This concept has also been postulated recently by Gutin [47] who hypothesized that vigorous physical exercise may contribute to MSC differentiation preference.

\section{MSC in Adipose Tissue: Influence of Obesity, Inflammation and Culture}

MSC have been derived from a variety of human and preclinical model adipose tissues (e.g. subcutaneous fat, fat pads in the knee [e.g. Hoffa’s fat pad, infrapatellar fat pad], brown fat, and abdominal fat) (reviewed in [8] [48]-[50]; and many others). In particular, MSC from subcutaneous fat via "liposuction” have been promoted as 
a ready source of cells for cartilage repair (reviewed in [8] [51]), and a number of clinical trials are on-going to evaluate their efficacy.

Interestingly, MSC derived from obese mice are reported to be altered in their differentiation potential and they are altered irrespective of tissue source (bone marrow, infrapatellar fat pad, subcutaneous fat), and the alterations appeared to be lineage-specific with the chondrogenic lineage specifically affected (discussed in [55]). Certainly obesity can lead to a metabolic disease or syndrome (reviewed in [52]-[54]; and others), so this is finding is not surprising at some levels. This metabolic syndrome also likely contributes to the altered inflammatory state observed in obesity, directly via adipokine secretion ([53] [54]; and others) or via subsequent amplification at systemic sites (discussed in [55]-[57]; and others). Obesity may also influence the proliferative potential of adipose-derived MSC [58], and therefore could alter regulation of these stem cells.

Acute joint inflammation due to an injury can also lead to alterations in the infrapatellar fat pad of the knee in ovine models [59], and transient alterations in adipokine expression [59] and MSC levels (Solbak et al., in preparation). As yet, it is not yet clear as to whether such inflammation leads to altered lineage differentiation.

Finally, merely culturing adipose-derived MSC in monolayer culture is also reported to alter lineage-specific differentiation [60], so care must be taken when making conclusions regarding adipose-tissue derived cells. Certainly culturing cells on plastic, in the presence of specific growth mediators, or serum has the potential to impact the MSC and influence the ability to translate in vitro findings to the in vivo condition.

These findings with MSC and other cells in adipose tissues are likely also relevant to the above discussion on the "fatty infiltration" of muscle, and bone marrow in response to an altered environment of muscle weakness, microgravity and prolonged bed rest. That is, these MSC populations are dynamic and respond to altered environments (e.g. loss of mechanical integrity, diet-induced obesity). In the case of diet-induced adiposity, it is clear there are still a large number of MSC in the tissues. Whether the MSC are contributing to the obesity (differentiation to adipocytes), as well as maintaining proliferation of the MSC compartment is possible, but not proven at this point. What is also unknown is whether the MSC compartment in muscle and bone marrow is also maintained in the tissues as the fatty infiltrate occurs. Thus, this should be a focus for future studies. The findings from such studies should either support or refute the premise that the adipose lineage for MSC differentiation is a "default" lineage when the mechanical environment is compromised.

\section{Why Are There So Many MSC in Adipose Tissues, and Could They Play a Role in Obesity When Regulation Is Compromised/Dysregulated?}

As discussed above, it is clear that MSC/MPC are present in a variety adipose tissues. The numbers decline with age, and obesity can apparently influence the functionality of such cells. Also with age, the incidence of lipid deposition in various compartments (e.g. subcutaneous fat vs abdominal fat in males vs females with age) increases. All of the above beg the question, why are there so many MSC/MPC in adipose tissues, and could their dysregulation be a contributing factor in obesity development? If so, then MSC/MPC leading to the adipose lineage may be a potential target for interventions (e.g. new drug therapies) to regulate MSC/MPC in both prolonged space flight, prolonged bed rest, and in some forms of obesity (discussed above and in [45]).

This concept is not entirely new as a number of reports have indicated that perhaps interfering with MSC differentiation towards the adipocyte lineage [61]-[64], or even replacement of neural MSC in the hypothalamus [56] [65]-[67] could modulate obesity-related events. Some reports have even postulated certain molecules could be potential molecular targets for limiting such pathways [61]-[64] [68] [69].

While performed prior to the onset of most information on MSC, a set of studies from the author's laboratory using (NZB x NZW) F1 mice (referred to as NZB/W mice) may also provide some clues in this regard. This strain of mice develop large deposits of subcutaneous and intra-abdominal fat as they mature and age, reaching weights that are nearly double that of parental strain animals or younger animals. Treatment of females of the NZB/W strain with daily injections of lithium chloride ( $\mathrm{LiCl}$ ) leads to a nearly complete inhibition of the development of fat deposits over months, and there was a "re-activation" of fat deposition after treatment was discontinued [70]-[72]. While MSC in these animals were not assessed, more recent studies have indicated that $\mathrm{LiCl}$ treatment leads to inhibition of expression of adipocyte lineage genes in vitro with human bone-morrow-derived MSC [73]. Therefore, as lithium ion is a known inhibitor of GSK-3 and a modulator of WNT/beta-catenin pathway components, such studies should be revisited to ascertain whether the outcomes were due to impact on MSC stability and differentiation. Furthermore, as lithium ion treatment of aged MSC restores some of their functionality [74], possibly such treatment could allow for re-establishment of MSC regulation following compromise 
as discussed above. However, as lithium ions do have potential side-effects, studies in mice to follow up the above discussed studies may lead to identification of specific targets that can be modulated using new drugs and therapeutic modalities for application in human populations.

\subsection{Implications of Such Alterations in the MSC Compartment for Tissue Homeostasis and Repair}

The infiltration of tissues by lipids and fat deposits could not only affect tissue function, but also the ability to repair if indeed the move towards such fatty infiltrates is due to loss of regulatory control of the MSC with differentiation towards the adipocyte lineage. If the extent of such infiltrates/deposition becomes excessive, loss of normal function would likely be expected if the condition persisted. In bone marrow, which is also responsible for blood cell formation from other stem cells, crowding out the normal environment with fat could lead to impaired blood cell formation. This concept has already been postulated by Payne et al. [75]. Similarly, in muscle the infiltrates could impair muscle contractions and responsiveness to stimuli. Depending on the breadth of different tissue involvement, and the extent and duration of these changes, one may also see impaired function in the liver, heart, and potentially the brain. As discussed earlier, some of the changes associated with micro-gravity and prolonged bed rest exposure may be a form of accelerated aging, so identifying suitable targets to prevent such changes from happening in younger, otherwise healthy individuals or in model systems, may also assist in understanding the normal aging process.

Finally, the observations discussed above regarding what may be the result of MSC dysregulation could also have implications beyond the microgravity/surrogate domain. That is, the focus has been on altered regulation due to altered mechanical environments, but regulation compromised by genetic, epigenetic and other biological factors could also have relevance to development and progression of obesity. That is, the MSC may play a direct participatory role in obesity development and progression in some people (discussed in [76]-[78]; and others). Such a role has prompted search for anti-obesity drugs that target MSC (for example, [79]). However, this challenge is complicated by the heterogeneity of MSC [2], even those within adipose tissues (discussed in [80]).

\subsection{Implications of Such Alterations in the MSC Compartment Regarding Tissue Engineering Potential}

As mentioned earlier, a number of clinical trials are on-going with adipose tissue derived MSC and such cells have been proposed to be used for cartilage tissue engineering ([51]; and others). Furthermore, a number of centers are using MSC from various tissues to inject into joints of patients with osteoarthritis or sports injuries in order to decrease symptoms (e.g. pain) or improve tissue repair.

Other centers are using MSC to generate Tissue Engineered Constructs (TEC) in attempts to repair cartilage defects, as well as other injured tissues. Thus, attempts to use MSC from tissues of individuals compromised by prolonged bed rest, or other "weightlessness" environments may lead to less than ideal outcomes, either at the generation stage, or the outcome stage after implantation as the TEC adapts to the in vivo environment.

Finally, most studies report proliferation and differentiation of MSC in vitro in the absence of mechanical loading. The above discussion certainly indicates that a lack of loading can influence MSC outcomes, and therefore, studies should likely be performed in the presence of mechanical loading that is appropriate for generating TEC for specific applications (e.g. tensile loading, shear loading, compressive loading, etc.). Optimizing loading for specific TEC applications may minimize some of the heterogeneity observed in mixed populations and yield better outcomes.

\section{Acknowledgements}

The author thanks Dr. Yamini Achari for her review of the manuscript, as well as colleagues and trainees in the McCaig Institute for Bone \& Joint Health (Calgary), the Centre for Hip Health and Mobility (Vancouver), the Technical University of Dresden (Germany), the University of Waterloo and the University of Toronto for discussions and interactions over the past decade which helped frame the above discussions. Studies from the author's laboratory were supported by operating grants from the Canadian Space Agency (030SR.9F007-02-216), Alberta Innovates Health Solutions (2008170 and 200700596), and a salary award to DAH (Calgary Foundation-Grace Glaum Professorship). 


\section{References}

[1] Hart, D.A. (2014) Perspectives on Endogenous and Exogenous Tissue Engineering Following Injury to Tissues of the Knee. Journal of Biomedical Science and Engineering, 7, 58-66. http://dx.doi.org/10.4236/jbise.2014.72009

[2] Hart, D.A. (2014) Why Mesenchymal Stem Cell/Progenitor Cell Heterogeneity in Specific Environments? —-Implications for Tissue Engineering Following Injury or Degeneration of Connective Tissues. Journal of Biomedical Science and Engineering, 7, 526-532.

[3] Ando, W., Kutcher, J.J., Krawetz, R., Sen, A., Nakamura, N., Frank, C.B. and Hart, D.A. (2014) Clonal Analysis of Synovial Fluid Stem Cells to Characterize and Identify Mesenchymal Stromal Cell/Mesenchymal Progenitor Cell Phenotypes in a Porcine Model: A Cell Source with Enhance Commitment to the Chondrogenic Lineage. Cytotherapy, Feb 12, E-Pub ahead of print.

[4] Borlongan, C.V., Glover, L.E., Tajiri, N., Kaneko, Y. and Freeman, T.B. (2011) The Great Migration of Bone Marrow-Derived Stem Cells towards the Ischemic Brain: Therapeutic Implications for Stroke and Other Neurological Disorders. Progress in Neurobiology, 95, 213-228. http://dx.doi.org/10.1016/j.pneurobio.2011.08.005

[5] Wu, Y. and Zhao, R.C. (2012) The Role of Chemokines in Mesenchymal Stem Cell Homing to the Myocardium. Stem Cell Reviews, 8, 243-250. http://dx.doi.org/10.1007/s12015-011-9293-z

[6] Li, L. and Jiang, J. (2011) Regulatory Factors of Mesenchymal Stem Cell Migration into Injured Tissues and Their Signal Transduction Mechanisms. Frontiers in Medicine, 5, 33-39. http://dx.doi.org/10.1007/s11684-011-0114-1

[7] Ando, W., Heard, B., Nakamura, N., Frank, C.B. and Hart, D.A. (2012) Ovine Synovial Membrane-Derived Mescenchymal Progenitor Cells Retain the Phenotype of the Original Tissue That Was Exposed to in Vivo Inflammation: Evidence for a Suppressed Chondrogenic Differentiation Potential of the Cells. Inflammation Research, 61, 599-608. http://dx.doi.org/10.1007/s00011-012-0450-x

[8] Gimble, J.M., Bunnell, B.A. and Guilak, F. (2012) Human Adipose-Derived Cells: An Update on the Transition to Clinical Translation. Regenerative Medicine, 7, 225-235. http://dx.doi.org/10.2217/rme.11.119

[9] Fehrer, C. and Lepperdinger, G. (2005) Mesenchymal Stem Cell Aging. Experimental Gerontology, 40, 926-930. http://dx.doi.org/10.1016/j.exger.2005.07.006

[10] Batsali, A.K., Kastrinaki, M.C., Papadaki, H.A. and Pontikoglou, C. (2013) Mesenchymal Stem Cells Derived from Wharton's Jelly of the Umbilical Cord: Biological Properties and Emerging Clinical Applications. Current Stem Cell Research and Therapeutics, 8, 144-155. http://dx.doi.org/10.2174/1574888X11308020005

[11] Deasy, B.M., Schugar, R.C. and Huard, J. (2008) Sex Differences in Muscle-Derived Stem Cells and Skeletal Muscle. Critical Reviews in Eukaryotic Gene Expression, 18, 173-188. http://dx.doi.org/10.1615/CritRevEukarGeneExpr.v18.i2.60

[12] Herrmann, J.L., Abarbanell, A.M., Weil, B.R., Manukyan, M.C., et al. (2010) Gender Dimorphisms in Progenitor and Stem Cell Function in Cardiovascular Disease. Journal of Cardiovascular and Translational Research, 3, $103-113$. http://dx.doi.org/10.1007/s12265-009-9149-y

[13] Kim, J.H., Jung, Y., Kim, B.S. and Kim, S.H. (2013) Stem Cell Recruitment and Angiogenesis of Neuropeptide Substance P Coupled with Self-Assembly Peptide Nanofiber in a Mouse Hind Limb Ischemia Model. Biomaterials, 34, 1657-1668. http://dx.doi.org/10.1016/j.biomaterials.2012.11.008

[14] Horie, M., Sekiya, I., Muneta, T., Ichinose, S., et al. (2009) Intra-Articular Injected Synovial Stem Cells Differentiate into Meniscal Cells Directly and Promote Meniscal Regeneration without Mobilization to Distant Organs in Rat Massive Meniscal Defects. Stem Cells, 27, 878-887. http://dx.doi.org/10.1634/stemcells.2008-0616

[15] Gharaibeh, B., Lavasani, M., Cummins, J.H. and Huard, J. (2011) Terminal Differentiation Is Not a Major Determinant for the Success of Stem Cell Therapy-Cross-Talk between Muscle-Derived Stem Cells and Host Cells. Stem Cell Research and Therapeutics, 2, 31. http://dx.doi.org/10.1186/scrt72

[16] Harris, Q., Seto, J., O’Brien, K., Lee, P.S., Kondo, C., Heard, B.J., Hart, D.A. and Krawetz, R.J. (2013) Monocyte Chemotactic Protein-1 Inhibits Chondrogenesis of Synovial Mesenchymal Progenitor Cells: An in Vitro Study. Stem Cells, 31, 2253-2265. http://dx.doi.org/10.1002/stem.1477

[17] Krawetz, R., Wu, Y.E., Martin, L., Rattner, J.B., Matyas, J.R. and Hart, D.A. (2012) Correction: Synovial Fluid Progenitors Expressing CD90+ from Normal but Not Osteoarthritis Joints Undergo Chondrogenic Differentiation without Micro-Mass Culture. PLoS ONE, 7, Article ID: e43616. http://dx.doi.org/10.1371/annotation/ace75296-7ec7-4193-ac91-5d68cfe5073e

[18] Hart, D.A., Frank, C.B. and Bray, R.C. (1995) Inflammatory Processes in Repetitive Motion and Over-Use Syndromes: Potential Role of Neurogenic Mechanisms in Tendons and Ligaments. In: Gordon, S.L., Blair, S.J. and Fine, L.J., Eds., Repetitive Motion Disorders of the Upper Extremity, AAOS, Park Ridge, Illinois, 247-262.

[19] Hart, D.A., Frank, C.B., Kydd, A., Ivie, T., et al. (2005) Neurogenic, Mast Cell and Gender Variables in Tendon Biology: Potential Role in Chronic Tendinopathy. In: Muffulli, N., Renstrom, P. and Leadbetter, W., Eds., Tendinopathy: 
Basic Science and Clinical Management, Springer-Verlag, London, 40-48.

[20] Monument, M.J., Hart, D.A., Salo, P.T., Befus, A.D. and Hildebrand, K.A. (2013) Posttraumatic Elbow Contractures: Targeting Neuroinflammatory Fibrogenic Mechanisms. Journal of Orthopaedic Science, 18, 869-877. http://dx.doi.org/10.1007/s00776-013-0447-5

[21] Monument, M.J., Hart, D.A., Salo, P.T., Befus, A.D. and Hildebrand, K.A. (2014) Neuro-Inflammatory Mechanisms of Connective Tissue Fibrosis: Targeting Neurogenic and Mast Cell Contributions. Advances in Wound Care, in press. http://dx.doi.org/10.1089/wound.2013.0509

[22] Hess, R., Douglas, T., Myers, K.A., Rentsch, C., Worch, H., Shrive, N.G., Hart, D.A. and Scharnweber, D. (2010) Hydrostatic Pressure (HP) Stimulation of Human Mesenchymal Stem Cells (hMSC) Seeded on Collagen-Based Artificial Extracellular Matrices. Journal of Biomechanical Engineering, 132, Article ID: 021001. http://dx.doi.org/10.1115/1.4000194

[23] Cao, B. and Huard, J. (2004) Muscle-Derived Stem Cells. Cell Cycle, 3, 104-107. http://dx.doi.org/10.4161/cc.3.2.644

[24] Usas, A., Maciulaitis, J., Maciulaitis, R., Jakuboniene, N., Milašius, A. and Huard, J. (2011) Skeletal Muscle-Derived Stem Cells: Implications for Cell-Mediated Therapies. Medicina (Kaunas), 47, 469-479.

[25] Chen, C.W., Corselli, M., Peault, B. and Huard, J. (2012) Human Blood-Vessel-Derived Stem Cells for Tissue Repair and Regeneration. Journal of Biomedicine and Biotechnology, 2012, Article ID: 597439. http://dx.doi.org/10.1155/2012/597439

[26] Longino, D., Butterfield, T.A. and Herzog, W. (2005) Frequency and Length-Dependent Effects of Botulinum ToxinInduced Muscle Weakness. Journal of Biomechanics, 38, 609-613. http://dx.doi.org/10.1016/j.jbiomech.2004.04.017

[27] Longino, D., Frank, C., Leonard, T.R., Vaz, M.A. and Herzog, W. (2005) Proposed Model of Botulinum Toxin-Induced Muscle Weakness in the Rabbit. Journal of Orthopaedic Research, 23, 1411-1418. http://dx.doi.org/10.1016/j.orthres.2005.02.016

[28] Leumann, A., Longino, D., Fortuna, R., Leonard, T., Vaz, M., Hart, D.A. and Herzog, W. (2012) Altered Cell Metabolism in Tissues of the Knee Joint in a Rabbit Model of Botulinum Toxin A-Induced Quadriceps Muscle Weakness. Scandinavian Journal of Medicine \& Science in Sports, 22, 776-782. http://dx.doi.org/10.1111/j.1600-0838.2011.01309.x

[29] Herbison, G.J. and Talbot, J.M. (1985) Muscle Atrophy during Space Flight: Research Needs and Opportunities. Physiologist, 28, 520-527.

[30] Hawkey, A. (2003) The Physical Price of a Ticket into Space. Journal of the British Interplanetary Society, 56, 152159.

[31] Narici, M.V. and de Boer, M.D. (2011) Disuse of the Musculo-Skeletal System in Space and on Earth. European Journal of Applied Physiology, 111, 403-420. http://dx.doi.org/10.1007/s00421-010-1556-X

[32] Smith, S.M., Heer, M.A., Shackelford, L.C., Sibonga, J.D., Ploutz-Snyder, L. and Zwart, S.R. (2012) Benefits for Bone from Resistance Exercise and Nutrition in Long-Duration Spaceflight: Evidence from Biochemistry and Densitometry. Journal of Bone and Mineral Research, 27, 1896-1906. http://dx.doi.org/10.1002/jbmr.1647

[33] Heer, M., Kamps, N., Biener, C., Korr, C., et al. (1999) Calcium Metabolism in Microgravity. European Journal of Medical Research, 4, 357-360.

[34] Rittweger, J., Gunga, H.C., Felsenberg, D. and Kirsch, K.A. (1999) Muscle and Bone-Aging and Space. Journal of Gravitational Physiology, 6, P133-P136.

[35] Biolo, G., Heer, M., Narici, M. and Strollo, F. (2003) Microgravity as a Model of Aging. Current Opinion in Clinical Nutrition and Metabolic Care, 6, 31-40. http://dx.doi.org/10.1097/00075197-200301000-00006

[36] Vernikos, J. and Schneider, V.S. (2010) Space, Gravity and the Physiology of Aging: Parallel or Convergent Disciplines? A Mini-Review. Gerontology, 56, 157-166. http://dx.doi.org/10.1159/000252852

[37] Stein, T.P. and Wade, C.E. (2005) Metabolic Consequences of Muscle Disuse Atrophy. Journal of Nutrition, 135, 1824S-1828S.

[38] LeBlanc, A.D., Spector, E.R., Evans, H.J. and Sibonga, J.D. (2007) Skeletal Responses to Space Flight and the Bed Rest Analog: A Review. Journal of Musculoskeletal and Neuronal Interactions, 7, 33-47.

[39] Jost, P.D. (2008) Simulating Human Space Physiology with Bed Rest. Hippokratia, 12, 37-40.

[40] Kos, O., Hughson, R.L., Hart, D.A., Clement, G., Frings-Meuthen, P., Linnarsson, D., et al. (2014) Elevated Serum Soluble CD200 and CD200R as Surrogate Markers of Bone Loss under Bed Rest Conditions. Bone, 60, 33-40. http://dx.doi.org/10.1016/j.bone.2013.12.004

[41] Trudel, G., Payne, M., Madler, B., Ramachandran, N., Lecompte, M., Wade, C., Biolo, G., Blanc, S., Hughson, R., Bear, L. and Uhthoff, H.K. (2009) Bone Marrow Fat Accumulation after 60 Days of Bed Rest Persisted 1 Year Activi- 
ties Were Resumed along with Hemopoietic Stimulation: The Women International Space Simulation of Exploration Study. Journal of Applied Physiology (1985), 107, 540-548.

[42] Trudel, G., Coletta, E., Cameron, I., Belavy, D.L., Lecompte, M., Armbrecht, G., Felsenberg, D. and Uhthoff, H.K. (2012) Resistive Exercises, with or without Whole Body Vibration, Prevent Vertebral Marrow Fat Accumulation during 60 Days of Head-Down Tilt Bed Rest in Men. Journal of Applied Physiology (1985), 112, 1824-1831.

[43] Wronski, T.J. and Morey, E.R. (1982) Skeletal Abnormalities in Rats Induced by Simulated Weightlessness. Metabolic Bone Disease and Related Research, 4, 69-75. http://dx.doi.org/10.1016/0221-8747(82)90011-X

[44] Myers, V.E., Zayzafoon, M., Douglas, J.T. and McDonald, J.M. (2005) RhoA and Cytoskeletal Disruption Mediate Reduced Osteoblastogenesis and Enhanced Adipogenesis of Human Mesenchymal Stem Cells in Modeled Microgravity. Journal of Bone and Mineral Research, 20, 1858-1866. http://dx.doi.org/10.1359/JBMR.050611

[45] Luu, Y.K., Capilla, E., Rosen, C.J., Gilsanz, V., Pessin, J.E., Judex, S. and Rubin, C.T. (2009) Mechanical Stimulation of Mesenchymal Stem Cell Proliferation and Differentiation Promotes Osteogenesis While Preventing Dietary-Induced Obesity. Journal of Bone and Mineral Research, 24, 50-61. http://dx.doi.org/10.1359/jbmr.080817

[46] Luu, Y.K., Pessin, J.E., Judex, S., Rubin, J. and Rubin, C.T. (2009) Mechanical Signals as a Non-Invasive Means to Influence Mesenchymal Stem Cell Fate, Promoting Bone and Suppressing the Fat Phenotype. Bonekey Osteovision, 6, 132-149.

[47] Gutin, B. (2013) How Can We Help People to Develop Lean and Healthy Bodies? A New Perspective. Research Quarterly in Exercise and Sport, 84, 1-5. http://dx.doi.org/10.1080/02701367.2013.762324

[48] Faustini, M., Bucco, M., Chiapanidas, T., Lucconi, G., Marazzi, M., Tosca, M.C., et al. (2010) Nonexpanded Mesenchymal Stem Cells for Regenerative Medicine: Yield in Stromal Vascular Fraction from Adipose Tissues. Tissue Engineering Part C: Methods, 16, 1515-1521. http://dx.doi.org/10.1089/ten.tec.2010.0214

[49] Wickham, M.Q., Erickson, G.R., Gimble, J.M., Vail, T.P. and Guilak, F. (2003) Multipotent Stomal Cells Derived from the Infrapatellar Fat Pad of the Knee. Clinical Orthopedics and Related Research, 412, 196-212. http://dx.doi.org/10.1097/01.blo.0000072467.53786.ca

[50] Orbay, H., Tobita, M. and Mizuno, H. (2012) Mesenchymal Stem Cells Isolated from Adipose and Other Tissues: Basic Biological Properties and Clinical Applications. Stem Cells International, 2012, Article ID: 461718. http://dx.doi.org/10.1155/2012/461718

[51] Guilak, F., Awad, H.A., Fermor, B., Leddy, H.A. and Gimble, J.M. (2004) Adipose-Derived Adult Stem Cells for Cartilage Tissue Engineering. Biorheology, 41, 389-399.

[52] Wu, C.L., Diekman, B.O., Jain, D. and Guilak, F. (2013) Diet-Induced Obesity Alters the Differentiation Potential of Stem Cells Isolated from Bone Marrow, Adipose Tissue and Infrapatellar Fat Pad: The Effects of Free Fatty Acids. International Journal of Obesity (London), 37, 1079-1087. http://dx.doi.org/10.1038/ijo.2012.171

[53] Hassan, M., Latif, N. and Yacoub, M. (2012) Adipose Tissue: Friend or Foe? Nature Reviews Cardiology, 9, 689-702. http://dx.doi.org/10.1038/nrcardio.2012.148

[54] Fietta, P. and Delsante, G. (2013) Focus on Adipokines. Theoretical Biology Forum, 106, 103-129.

[55] Purkayastha, S. and Cai, D.S. (2013) Neuroinflammatory Basis of Metabolic Syndrome. Molecular Metabolism, 2, 356-363. http://dx.doi.org/10.1016/j.molmet.2013.09.005

[56] Purkayastha, S. and Cai, D.S. (2013) Disruption of Neurongenesis by Hypothatlamic Inflammation in Obesity or Aging. Reviews in Endocrine and Metabolic Disorders, 14, 351-356. http://dx.doi.org/10.1007/s11154-013-9279-z

[57] Jialal, I., Kaur, H. and Devaraj, S. (2014) Toll-Like Receptor Status in Obesity and Metabolic Syndrome: A Translational Perspective. Journal of Clinical Endocrinology and Metabolism, 99, 39-48. http://dx.doi.org/10.1210/jc.2013-3092

[58] Kim, Y.J., Hwang, S.H., Cho, H.H., Shin, K.K., Bae, Y.C. and Jung, J.S. (2012) MicroRNA 21 Regulates the Proliferation of Human Adipose Tissue-Derived Mesenchymal Stem Cells and High-Fat Diet-Induced Obesity Alters microRNA 21 Expression in White Adipose Tissues. Journal of Cellular Physiology, 227, 183-193. http://dx.doi.org/10.1002/jcp.22716

[59] Solbak, N.M., Heard, B.J., Achari, Y., Chung, M., Shrive, N.G., Frank, C.B. and Hart, D.A. (2014) Persistant Molecular and Histologic Changes in the Infrapatellar Fat Pad Following Idealized Anterior Cruciate Ligament Surgery May Compromise the Long Term Integrity of the Ovine Knee. Manuscript Submitted (20 April, 2014).

[60] Estes, B.T., Diekman, B.O. and Guilak, F. (2008) Monolayer Cell Expansion Conditions Affect the Chondrogenic Potential of Adipose-Derived Stem Cells. Biotechnology and Bioengineering, 99, 986-995. http://dx.doi.org/10.1002/bit.21662

[61] Kang, T., Lu, W., Xu, W., Anderson, L., Bacanamwo, M., Thompson, W., Chen, Y.E. and Liu, D. (2013) MicroRNA27 (miR-27) Targets Prohibitin and Impairs Adipocyte Differentiation and Mitochondrial Function in Human Adipose- 
Derived Stem Cells. Journal of Biological Chemistry, 288, 34394-34402. http://dx.doi.org/10.1074/jbc.M113.514372

[62] Oger, F., Gheeraet, C., Mogilenko, D., Benomar, Y., Molendi-Coste, O., Bouchaert, E., et al. (2014) Cell-Specific Dysregulation of MicroRNA Expression in Obese White Adipose Tissue. The Journal of Clinical Endocrinology \& Metabolism, 23, Article ID: jc20134259. http://dx.doi.org/10.1210/jc.2013-4259

[63] Grunberg, J.R., Hammarstedt, A., Hedjazifar, S. and Smith, U. (2014) The Novel Secreted Adipokine WNT1-Inducible Signaling Pathway Protein 2 (WISP2) Is a Mesenchymal Cell Activator of Canonical WNT. Journal of Biological Chemistry, 289, 6899-6907.

[64] Lee, Y.H., Mottillo, E.P. and Granneman, J.G. (2014) Adipose Tissue Plasticity from WAT to BAT and in between. Biochimica et Biophysica Acta, 1842, 358-369. http://dx.doi.org/10.1016/j.bbadis.2013.05.011

[65] Li, J.X., Tang, Y.Z., Purkayastha, S., Yan, J.Q. and Cai, D.S. (2014) Control of Obesity and Glucose Intolerance via Building Neural Stem Cells in the Hypothalamus. Molecular Metabolism, 3, 313-324. http://dx.doi.org/10.1016/j.molmet.2014.01.012

[66] Cai, D.S. (2013) Neuroinflammation and Neurodegeneration in Overnutrition-Induced Diseases. Trends in Endocrinology and Metabolism, 24, 40-47. http://dx.doi.org/10.1016/j.tem.2012.11.003

[67] Billion, N., Monteiro, M.C. and Dani, C. (2008) Developmental Origin of Adipocytes: New Insights into a Pending Question. Biology of the Cell, 100, 563-575. http://dx.doi.org/10.1042/BC20080011

[68] McGregor, R.A. and Choi, M.S. (2011) MicroRNAs in the Regulation of Adipogenesis and Obesity. Current Molecular Medicine, 11, 304-316. http://dx.doi.org/10.2174/156652411795677990

[69] Guo, Y.X., Mo, D.L., Zhang, Y., Cong, P.Q., Xiao, S.Q., He, Z.Y., Liu, X.H. and Chen, Y.S. (2012) MicroRNAome Comparison between Intramuscular and Subcutaneous Vascular Stem Cell Adipogenesis. PLoS ONE, 7, Article ID: e45410. http://dx.doi.org/10.1371/journal.pone.0045410

[70] Krause, G., Zhao, P., Martin, L., Fritzler, M., Benediktsson, H. and Hart, D.A. (1992) LiCl Prolongs Survival and Alters Disease Progression in the NZB/W Model of SLE. Lithium, 3, 61-67.

[71] Hart, D.A., Done, S.J., Benediktsson, H. and Lenz, S. (1994) Partial Characterization of the Enhanced Survival of Female NZB/W Mice Treated with Lithium Chloride. International Journal of Immunopharmacology, 16, 825-833. http://dx.doi.org/10.1016/0192-0561(94)90056-6

[72] Hart, D.A. and Lenz, S.P. (1997) Multiple Daily Injections of NZB/W Mice with LiCl Leads to the Long-Term Survival of a High Percentage (80\%) of the Animals. Journal of Trace and Microprobe Techniques, 15, 219-227.

[73] Satija, N.K., Sharma, D., Afrin, F., Tripathi, R.P. and Gangenahalli, G. (2013) High Throughput Transcriptome Profiling of Lithium Stimulated Human Mesenchymal Stem Cells Reveals Priming towards Osteoblastic Lineage. PLoS ONE, 8, Article ID: e55769.

[74] Brunt, K.R., Zhang, Y., Mihic, A., Li, M., Li, S.H., et al. (2012) Role of WNT/Beta-Catenin Signaling in Rejuvenating Myogenic Differentiation of Aged Mesenchymal Stem Cells from Cardiac Patients. American Journal of Pathology, 181, 2067-2078. http://dx.doi.org/10.1016/j.ajpath.2012.08.021

[75] Payne, M.W., Uhthoff, H.K. and Trudel, G. (2007) Anemia of Immobility: Caused by Adipocyte Accumulation in the Bone Marrow. Medical Hypotheses, 69, 778-786. http://dx.doi.org/10.1016/j.mehy.2007.01.077

[76] Laharrague, P. and Casteilla, L. (2010) The Emergence of Adipocytes. Endocrine Development, 19, 21-30.

[77] Maijka, S.M., Barak, Y. and Klemm, D.J. (2011) Concise Review: Adipocyte Origins: Weighing the Possibilities. Stem Cells, 29, 1034-1040.

[78] Cignarelli, A., Perrini, S., Ficarella, R., Peschechera, A., Nigroa, P. and Giorgino, F. (2012) Human Adipose Tissue Stem Cells: Relevance in the Pathophysiology of Obesity and Metabolic Diseases and Therapeutic Applications. Expert Reviews in Molecular Medicine, 14, e19. http://dx.doi.org/10.1017/erm.2012.13

[79] Hwang, J.H., Moon, S.A., Lee, C.H., Byun, M.R., et al. (2012) Idesolide Inhibits the Adipogenic Differentiation of Mesenchymal Cells through the Suppression of Nitric Oxide Production. European Journal of Pharmacology, 685, 218-223. http://dx.doi.org/10.1016/j.ejphar.2012.04.018

[80] Bourin, P., Bunnell, B.A., Casteilla, L., Dominici, M., Katz, A.J., March, K.L., Redl, H., Rubin, J.P., Yoshimura, K. and Gimble, J.M. (2013) Stromal Cells from the Adipose Tissue-Derived Stromal Vascular Fraction and Culture Expanded Adipose Tissue-Derived Stromal/Stem Cells: A Joint Statement of the International Federation for Adipose Therapeutics and Science (IFATS and the International Society for Cellular Therapy (ISCT). Cytotherapy, 15, 641-648. http://dx.doi.org/10.1016/j.jcyt.2013.02.006 
Scientific Research Publishing (SCIRP) is one of the largest Open Access journal publishers. It is currently publishing more than 200 open access, online, peer-reviewed journals covering a wide range of academic disciplines. SCIRP serves the worldwide academic communities and contributes to the progress and application of science with its publication.

Other selected journals from SCIRP are listed as below. Submit your manuscript to us via either submit@scirp.org or Online Submission Portal.
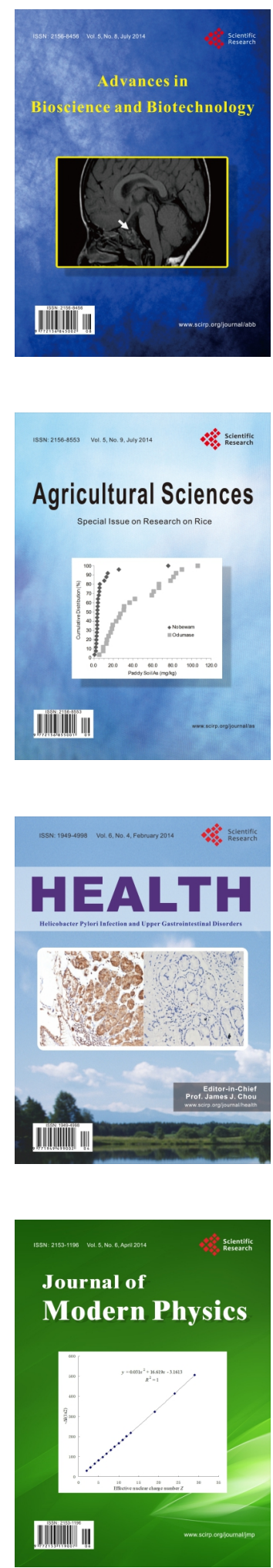
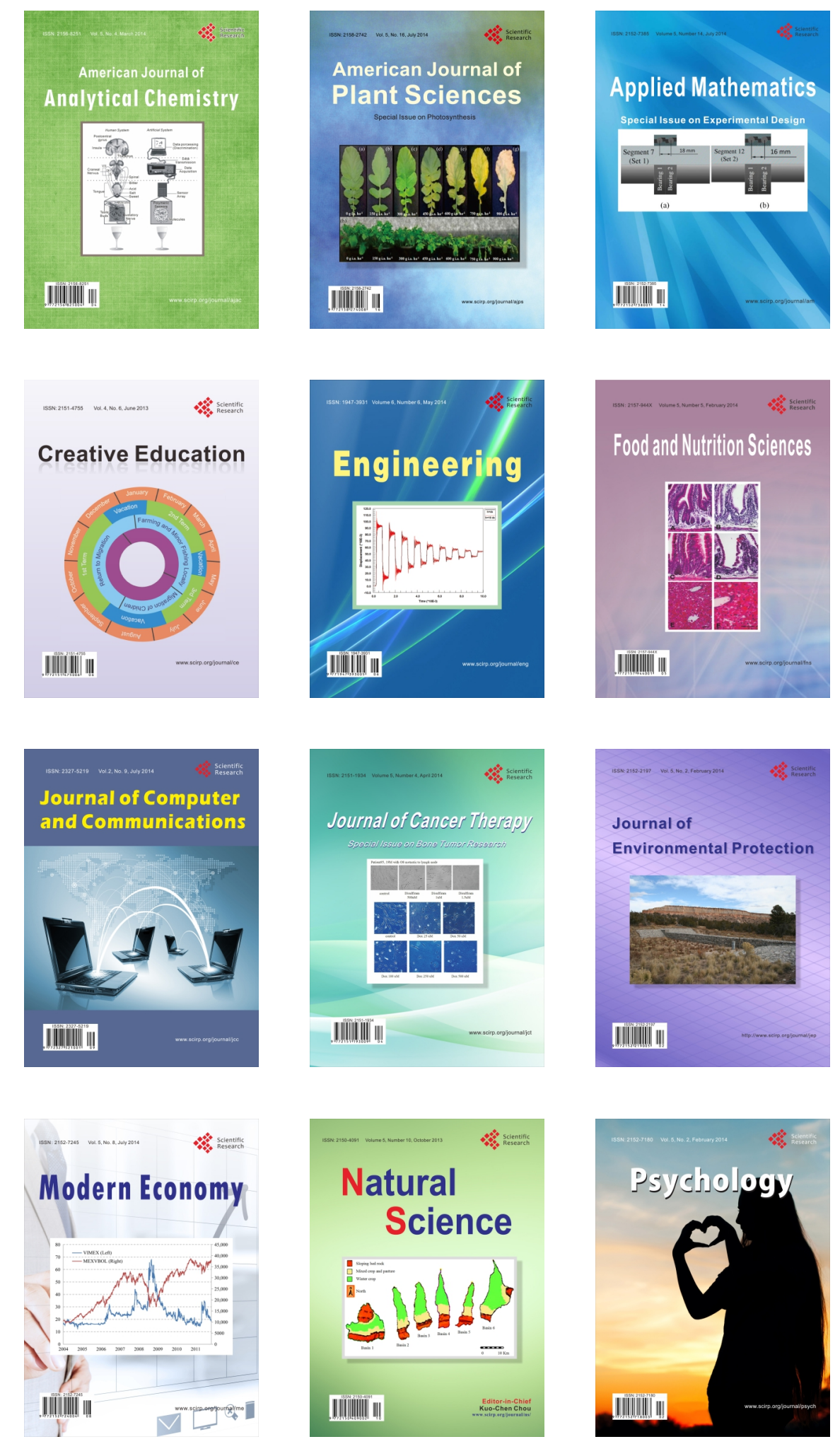